\title{
Equoterapia como ação extensionista de inclusão social e escolar
}

http://dx.doi.org/10.11606/1807-5509202000034nesp029

\section{Resumo}

Este artigo tem por objetivo apresentar as ações de um projeto de extensão universirária que traz como foco principal a inclusão social e escolar, em parceria com Ministério Público do Trabalho, Associação de Pais e Amigos do Expecional e Universidade Federal da Paraiba por meio da prática de equoterapia. As ações foram realizadas de 2016 a 2018, por meio de sessões semanais, com duração de 20 a 30 minutos, a 24 pessoas com deficiência, sendo atendidas por especialistas na área de fisioterapia, fonoaudiologia, psicologia, educador fisico, pedagoga e equitadores (universitários extensionistas). Houve melhoras quanto à postura corporal, a oralidade, propriopercepção, tónus muscular, aspectos social entre outros. Quanto à formação social dos universitários podemos apontar envolvimento social e responsabilidade no aspecto humano e profissional. Os desafios a serem enfretados é a falta de recursos financeiros para ampliação do projeto e fortalecimento das redes sociais para aceitação da diversidade.

Palavras-chave: APAE; Atendimento especializado; Pessoas com deficiência.

\section{Introdução}

Desde a última década do século passado, o movimento de inclusão social e escolar tem crescido no Brasil, sobretudo, em relação ao atendimento às pessoas com deficiência em diferentes segmentos sociais.

A inclusão social pressupóe que todas as pessoas, independente de suas características físicas, sociais, econômicas e culturais tenham garantido os seus direitos e, sobretudo, possam exercer sua cidadania com boa qualidade de vida. Esse pressuposto é garantido pela Constituição Federal Brasileira ${ }^{1}$, em seus artigos $3^{\circ}, 5^{\circ}, 206$ a 208 , em que reconhecem que todos os membros da sociedade são iguais perante a lei e que em função das necessidades especiais de cada pessoa, açóes comunitárias e políticas públicas devem se constituir para contribuir na formaçâo de uma sociedade inclusiva (Resolução da ONU 78/93) e mais justa².

Especificamente na cidade de Areia, a educaçâo especial e os atendimentos especiais têm se consolidado por meio da Apae (Associaçáo de Pais e Amigos do Expecional). Esta é a única instituiçâo de atendimento especializado na cidade, e ainda atende demandas de Arara, Remígio, Pilóes, Alagoa Grande e outras ao seu entorno. A Apae de Areia, vem construindo sua história, desde sua criação em 2003, com atendimento educacional especializado para pessoas com necessidades especiais. Esta instituição não tem fins lucrativos e tem recebido o apoio da UFPB desde 2010, por meio da extensão universitária, com diferentes projetos educacionais. E, em 2015, com o financiamento do Ministério Público do Trabalho (MPT) e com a parceria da UFPB, houve a implantação da Equoterapia, que iniciou seus atendimentos em março de 2016. Atualmente, atende cerca de 24 pessoas com necessidades educacionais especiais, por meio de atendimentos agendados e acompanhamentos orientados por uma equipe multidisciplinar, composta por voluntários, profissionais e estudantes da UFPB (de diferentes cursos).

A Apae além do atendimento equoterápico tem atendimento educacional para crianças, jovens e
* Universidade Federal da Paraíba, Areia, PB, Brasil.

** Associação de Pais e Amigos do Expecional - APAE, Areia, PB, Brasil.

$* * *$ Universidade Federal de Juiz de Fora, Juiz de Fora,

MG, Brasil. 
adultos com diversas necessidades especiais. Desde 2003, a Apae com a participação de pais, amigos e voluntários militantes na causa de inclusão escolar de crianças com deficiências e/ou necessidades especiais (nee), vem ampliando sua contribuição à sociedade. Atualmente, ela atende 64 jovens e crianças, sendo 24 o número de praticantes da equoterapia. Entre os atendimentos podemos apontar crianças e jovens com Autismo, Síndrome de Down, Paralisia Cerebral, Deficientes visuais e auditivos entre outras nee. A Apae é mantida por contribuições voluntárias e teve o título de Utilidade Pública Municipal no dia 07 de Maio de 2004 sob Lei no 605/2004.

O público atendido é oriundo de diversas cidades ao entorno da cidade de Areia, e é composto por famílias com baixíssimas condiçóes econômicas, o que dificulta o acesso aos diferentes atendimentos educacionais especializados que não são disponibilizados via Prefeitura. Boa parte desta população é da zona rural e frequenta a escola por meio de transporte coletivo disponível pela prefeitura ou em parceria ${ }^{3}$.

No atendimento educacional, a Apae atende os estudantes especiais, durante a semana, em dois diferentes turnos, estáo alguns deles, matriculados em escolas públicas da rede pública ou privada com bolsa de estudos. Neste contexto, a UFPB, por meio da extensão universitária pôde contribuir para consolidar as açóes da Apae ao corroborar com as açôes da equoterapia e educacional, promovendo por meio de momentos formativos e atendimento equoterapêutico que envolvem participação de bolsistas e voluntários como membros da equipe.

As açóes do projeto "Equoterapia: uma ação interdisciplinar para o atendimento de pessoas com necessidades especiais", estão vinculadas à parceria realizada com Apae, por meio do MPT e UFPB, em audiência pública, registrada em Ata de processo no 00298-1998-018-00-8, de 02 de julho de 2015; na qual professores da UFPB se comprometeram em colaborar com a equoterapia. Todavia, somente em 2016, iniciou-se as açôes de extensão, ano em que o MPT entregou a Apae uma área para a prática com os animais, chamada picadeiro. Esta ação extensionista se caracteriza com atividade vinculada às açóes curriculares, por exigir a participação de profissionais de diferentes áreas (interdisciplinaridade), as quais os graduandos (zootecnia, medicina veterinária, licenciaturas de Ciências Biológicas e Química) podem contribuir e aprender com a execução da equoterapia e colocar em prática seus conhecimentos acadêmicos como cuidados e saúde com o animal, atividades relacionadas à responsabilidade social para a construção de uma sociedade inclusiva e contribuir para melhorar as condições de atendimento às pessoas com necessidades especiais.

\section{A equoterapia: aspectos históricos e conceituais}

O termo equoterapia embora tendo sido criado em 1989, pela ANDE/Brasil (Associação Nacional de Equoterapia), apenas em 1997 foi reconhecida pelo Conselho Federal de Medicina como um recurso terapêutico de reabilitação motora e como um método educacional pela Instituição de Divisão de Ensino Especial da Secretaria de Educação do Distrito Federal. A equoterapia já tem uma longa história no tratamento do homem quanto às doenças e aos problemas neuromotores e/ou psicológico ${ }^{4}$. Mas, antes de atentarmos para os aspectos históricos, faz-se necessário um estudo etimológico da palavra para compreendermos o que é equoterapia. Equus de origem no latim associa-se a equino (cavalo); terapia associa-se a tratamento; sendo assim, a palavra equoterapia é a somatória de ambos os termos que traz um significado de tratamento para o ser humano por meio do cavalo, as suas condiçóes neuromotora e psicológica que pode contribuir no desenvolvimento global da criança e do adulto praticante ${ }^{4}$.

A ANDE/Brasil, em 1999, denominou equoterapia por três motivos: a) Homenagear o Latim, vernáculo do qual deriva o português adotando o radical Equo derivado de Equus; b) Homenagear Hipócrates que utilizava a palavra "Therapeia" para denominar a parte da medicina que trata da aplicação do conhecimento técnico científico no campo da reabilitaçáo. Por esta razão adotou-se a palavra terapia e; c) Por estarem adotando uma palavra ainda náo existente no dicionário nacional, poderiam adotar princípios e normas fundamentais para esta técnica, no Brasil $1^{5}$.

Sendo assim, para a $\mathrm{ANDE}^{4}$, a equoterapia é um método terapêutico educacional que utiliza o cavalo dentro de uma abordagem interdisciplinar, nas áreas de saúde, educação e equitação, buscando o desenvolvimento biopsicossocial de pessoas com deficiências e/ou com necessidades especiais (chamado na equoterapia de praticantes). A equoterapia é um dos poucos recursos que possibilitam uma maior participação, integração 
ou acompanhamento mais próximo por parte dos pais durante a sessão.

Segundo Cirillo", a "Equoterapia é um tratamento de reeducação motora e mental, que por meio de prática de atividades equestres e técnicas de equitação", pode favorecer o indivíduo no seu reestabelecimento e reabilitação de funções motoras e/ou cognitivas quando associadas às diferentes áreas de atendimento, sejam elas: fisioterapia, psicologia, educação física e pedagógica.

Segundo Alves ${ }^{7}$, a equoterapia pode ser uma terapia principal ou complementar, dependendo de sua patologia. O tratamento equoterápico pode proporcionar uma reabilitação global, uma vez que o indivíduo tem acesso a uma ajuda psicológica e psicossomática, por meio de uma equipe interdisciplinar e sessóes contínuas por um determindado tempo de atendimento. De acordo com BEZERRA ${ }^{8}$, a equoterapia deve ser desenvolvida como um tratamento de suporte, sem substituir o convencional, sendo elegível somente uma vez por semana; assim como pressupóe os princípios de inclusão escolar e social, que compreende que os atendimentos especializados são complementares aos convencionais e a educação regular. Estas, também, corroboram com WiCKERT ${ }^{9}$, em que afirma que a equoterapia é o processo de reabilitação de pessoas com deficiência e/ou com necessidades especiais, que utiliza o cavalo como alternativa terapêutica e com o acompanhamento de uma equipe de profissionais especializados, e que traz as pessoas com deficiência uma melhora possível, tanto física quanto psíquica. Sendo assim, entendemos que a equoterapia é um atendimento complementar aos convencionais e a educação, que podem contribuir no desenvolvimento biopiscossocial do indivíduo, favorecendo a construção da própria identidade, autoestima, autoconfiança, favorecimento nos aspectos sociais e interativos entre as pessoas e animal; assim como contribui para os aspectos fisiológicos e intelectuais do mesmo, pois melhora o tônus muscular, a desenvoltura, o equilíbrio, força muscular, relaxamento a atenção, a conscientização do próprio corpo e aperfeiçoamento da coordenação motora.

Outros aspectos a serem favorecidos, por meio da equoterapia e a intervenção dos profissionais interdisciplinares são: a fala, a linguagem, a lateralidade, o tato, a identificação das cores, a memória, o raciocínio, o senso de direção, a percepção auditiva e visual e a orientação espacial e temporal dos atendidos ${ }^{4,5}$.
Quanto aos aspectos históricos, podemos afirmar que a prática equestre com fins terapêuticos vem de longa data. Encontramos suas primeiras referências em Hipócrates (58-377 a. C.) prescrevendo a equitação como tratamento da insônia ${ }^{10}$.

FERREIRA $^{11}$ afirma que a equoterpia apresenta-se antes da idade de Cristo: "Já em 124 a. C., Asclepíades de Prussia (médico grego) indicou a equitaçáo para tratar a epilepsia e vários tipos de paralisia. Indicava os movimentos do cavalo a pacientes caquéticos, epiléticos, paralíticos, apopléticos, letárgicos, frenéticos e também para os acometidos de febre terçâ." Ferreira 11 ainda aponta que em "130199 d.C., Galeno, consolidador e divulgador dos conhecimentos da medicina ocidental como médico particular do Imperador Marco Aurélio, recomendou a prática da equitação como forma de fazer com que ele imperasse com mais rapidez, visto que era um pouco lento nas suas decisões."

Em 1569, Mecurialis (médico), em sua obra "De arte gymnastica", menciona uma observação feita por Galeno, de que a equitação ocupa uma posição de destaque entre os exercícios e ginásticas, pois exercita não só o corpo, mas também os sentidos.

$\mathrm{O}$ autor descreve os diferentes tipos de andamentos do cavalo que contribuem com o tratamento humano, comentava que a equitação aumentava o "calor natural" e remediava a "escassez de excreçôes"12. Assim como Alves ${ }^{7}$ e Freire ${ }^{13}$ alude que em 1681, a equitação era indicada para outros tipos de tratamento além de ser usado para se manter a forma e estabelecer equilíbrio emocional.

E em 1890, os primeiros estudos sobre as vibrações transmitidas ao cérebro pelos movimentos equestres, foi estudado pelo médico Zander, fisiatra e mecanoterapeuta, e professor, seguido dos trabalhos de pequisa do médico e professor alemão Dr. Detlvev Rieder. Este aferiu essas vibraçóes ao dorso do cavalo ao passo e, verificou que correspondiam exatamente aos valores descritos por ZANDER ${ }^{10,12}$. Como podemos constatar, a interação do cavalo com o homem está presente há milhões de anos, por várias geraçóes, com diversas finalidades e também para curar algumas enfermidades e/ou melhorar alguma necessidade especial.

Em suma, este artigo tem por objetivo apresentar o trabalho de extensão universitária, no campus 2, da UFPB, junto a APAE/Areia, no tocante aos atendimentos especializados por meio da equoterapia, no qual correlaciona as atividades de ensino, pesquisa em extensão a benefício da comunidade. 


\section{Método}

\section{Procedimentos: fazendo terapia por meio da extensão universitária}

Os procedimentos para a realização das açôes extensionistas se centralizaram em atendimentos de equoterapia com sessóes que duraram de 20 a 30 minutos. O tempo de cada seçáo variava, muito por conta do praticante, pois não é aconselhado que a equipe insista em um atendimento, no qual o praticante por algum motivo não esteja aceitando bem. As atividades aconteceram nas terças-feiras pela manhã, quintas e sextas-feiras manhã e tarde. Os praticantes foram divididos de forma que eram atendidos uma vez por semana nos horários previamente estabelecidos pela equipe e família, visando tanto a organização dos atendimentos como o melhor horário para os praticantes. As seçôes, costumeiramente, começavam às 7 horas da manhã e estendiam-se até 11 horas. As sessões eram realizadas por profissionais especializados e voluntários vinculados à APAE/Areia e à UFPB.

Os profissionais voluntários envolvidos eram: Fisioterapeuta; Psicólogo; Fonoaudiólogo; Pedagogo; Educador físico e Auxiliar-guia (equitador), sendo 1 estudante bolsista e 4 estudantes voluntários, após treinamento feito pelos coordenadores do Projeto de Extensão Universitária. Os 3 primeiros profissionais citados eram voluntários da APAE e os demais vinculados à UFPB.

Ainda para a realização da equoterapia como extensão universitária, havia professores dos cursos de medicina veterinária que cuidam da saúde animal e uma professora da Zootecnia que orienta as açóes de alimentaçáo e manejo animal para treinamento e cuidados dos cavalos. Quanto aos universitários, havia 1 bolsista e 4 voluntários, estes vinculados aos cursos de Medicina Veterinária, Zootecnia, Licenciatura em Biologia e Química, sob a orientação e coordenaçáo dos professores envolvidos e a coordenação do projeto.

Outras atividades complementares foram realizadas durante o projeto, para melhor acompanhamento e replanejamento das açóes da equoterapia durante o ano letivo pelos profissionais envolvidos. Dentre elas: orientação sobre as ações do pedagogo quanto ao atendimento educacional dos participantes e a equipe geral da equoterapia, quanto à aprendizagem e ao acompanhamento das pessoas com nee; orientação mensal quanto à alimentação e saúde do cavalo, com visitas periódicas; procedimentos médico veterinário, devido à necessidade de cirurgia do cavalo; elaboração de material de divulgação e acompanhamento das atividades da equoterapia na Apae; acompanhar a alimentação e nutrição animal, readequando-a para a manutenção da saúde do cavalo, mensalmente; reavaliação das pessoas com nee que já estavam em atendimento na equoterapia, no projeto de 2016 para 2018; e continuaram em 2019; avaliar cada praticante antes do início o tratamento; estabelecer os objetivos do tratamento para cada praticante e planejar as atividades a serem desenvolvidas; conduzir as sessóes de equoterapia, seguindo plano proposto para cada pessoa com nee; zelar permanentemente pela segurança dos praticantes; registros de acompanhamento e avaliação dos atendidos; reuniôes de equipe para discussão de casos em atendimento; apresentação das ações de equoterapia no Encontro Unificado de Extensão Universitária da UFPB, e por meio de redes sociais e rádio local sobre as açóes para divulgaçáo das açóes da equoterapia.

\section{O Público}

Foram atendidas 24 pessoas com necessidades especiais, de baixa condição financeira, conforme dados fornecidos pela Apae com as seguintes patologias: Microcefalia, Transtorno opositor desafiador, transtorno de atenção e hiperatividade, Deficiência auditiva; Deficiência intelectual; Paralisia cerebral; Autismo; Síndrome de Down; Síndromes diversas. Elas foram nomeadas como praticantes, assim como se prevê nas orientações da ANDE.

Os resultados aqui apresentados serão analisados à luz dos fundamentos teóricos associados à inclusão social e escolar.; e mais ainda, à luz dos fundamentos dos Direitos Humanos. Vale ressaltar que o espectro associado aos Direitos Humanos vincula-se a condição indissociável do conceito de direito ao sujeito, enquanto cidadão e ao princípio de dignidade. Muitos filósofos acreditam que os direitos guardam relação direta com o que pensamos sobre o que é ser humano e como deve ser sua relação social com os demais seres humanos. Sendo, assim, é mister afirmar que o ser humano é único e singular; e pela simples condiçẫo de ser humano, está sujeito ao reconhecimento da dignidade humana como condição social básica para 
sua existência e vida.

Assim, os resultados a serem apresentados mostrarão a importância da extensão e da pesquisa correlacionadas, para a consolidação dos Direitos humanos à população vulnerável constituída pelos praticantes atendidos pela Apae, a qual trabalha exclusivamente com voluntários associados a própria instituição ou a UFPB. Neste contexto, queremos aqui ratificar a hipótese de que a extensão universitária é uma alternativa para a consolidação dos Direitos Humanos quanto ao direito de acesso à educação e à saúde.

\section{Resultados}

As atividades equoterapêuticas, no Centro de Equoterapia da APAE de Areia, tiveram início em maio de 2016, com uma equipe multiprofissional já descrita. Foram inscritos 24 praticantes com diversos diagnósticos como, transtorno opositor desafiador, microcefalia, síndrome de Down, deficiência intelectual, autismo, transtorno de conduta e hiperatividade, deficiência auditiva, paralisia cerebral, síndrome de Rubstein, com uma sessão de 20 a $30 \mathrm{~min} / \mathrm{semana}$. As pessoas atendidas no Centro vêm das cidades de Remígio, Esperança, Pilóes, além da própria cidade de Areia, todas circunvizinhas ao campus 2 da UFPB.

Os resultados obtidos nestes anos de funcionamento foram muito satisfatórios. Notouse evolução dos praticantes no que se refere à coordenaçáo motora, equilíbrio, tônus muscular, a condição de controle e adequação postural, na marcha, diminuição de sialorréia nos praticantes com comprometimento na área motora e, consequentemente, desenvolvimento escolar para os que estáo matriculados em escolas regulares e/ou especiais. Em relação aos praticantes com comprometimento cognitivo e no desenvolvimento global notou-se evolução na interação social, comunicação oral espontânea, comunicação em Língua brasileira de Sinais (Libras), controle emocional, concentração, memória, autoestima, segurança, contato visual, diminuição da hiperatividade, da agressividade, e da ecolalia.

As avaliaçóes foram feitas baseadas nas observaçóes, anotações e vídeos registrados pela equipe multidisciplinar antes de iniciar o tratamento e durante as sessóes de equoterapia, e pelos depoimentos das famílias.

Considerando isto, listamos os resultados atingidos pelos praticantes em diferentes áreas: As sessóes equoterapêuticas realizadas tiveram por objetivo geral promover o desenvolvimento da linguagem oral e minimizar as dificuldades de socialização ocasionadas pelo autismo, quadro sindrômico que algumas crianças praticantes apresentam. No que diz respeito ao desenvolvimento da linguagem oral, foram traçados objetivos específicos como: promover o desenvolvimento dos aspectos cognitivos (atenção, concentração e memória), promover desenvolvimento da linguagem expressiva (emissão e intenção comunicativa) e promover o desenvolvimento das vocalizações. Esses objetivos foram trabalhados com uma praticante em cada sessão e realizados através de conversas espontâneas, brincadeiras lúdicas com livros de histórias infantis, bolinhas de sabăo, jogos de encaixe, bolas, jogos de associação de cores, fantoches, livros de números, jogos de memória. Também foram realizadas atividades e conversas dirigidas usando categorias semânticas de frutas, animais, cores, materiais de higiene pessoal e objetos utilizados no dia-a-dia da criança.

Para minimização das dificuldades de socialização foram traçados objetivos específicos como: promover melhor densenvolvimento nas relaçóes interpessoal e promover melhor interação social, que foram trabalhados durante todas as sessóes com aproximação do "praticante e animal" e "praticante e terapêutas", através de conversas espontâneas e dirigidas, atividades relacionadas ao cavalo (pentear e enfeitar o pelo e crina do cavalo; abraçar, beijar, limpar o cavalo; alimentar o cavalo) e atividades lúdicas que envolviam situaçóes do dia-a-dia da criança.

Em outro caso de autismo podemos constatar evolução no quadro de temperamento forte, apresentando sinais de agressividade ao ser contrariado e dificuldades em aceitar a palavra "não". Em relação à linguagem expressiva o praticante apresentou apenas palavras soltas como: "papai", "mamãe", "auau" (cachorro), "arro" (carro). Apresentou dificuldades para se relacionar com pessoas que não são do seu ambiente familiar.

Também se pode observar evolução no que desrespeito ao desenvolvimento da linguagem oral, para os quais foram traçados objetivos específicos 
como: promover o desenvolvimento dos aspectos cognitivos (atenção, concentração e memória), promover desenvolvimento da linguagem expressiva (emissão e intenção comunicativa) e promover o desenvolvimento das vocalizaçóes. Esses objetivos foram trabalhados com o praticante em cada sessão e realizados através de conversas espontâneas, brincadeiras lúdicas com livros de histórias infantis, bolinhas de sabão, jogos de encaixe, bolas, jogos de associação de cores, fantoches, livros de números, jogos de memória. Também foram realizadas atividades e conversas dirigidas usando categorias semânticas de frutas, animais, cores, materiais de higiene pessoal e objetos utilizados no dia-a-dia da criança.

Para minimização das dificuldades de socialização foram traçados objetivos específicos como: promover melhor desenvolvimento nas relaçóes interpessoal e promover melhor interação social, que foram trabalhados durante todas as sessões com aproximação do "praticante e animal" e "praticante e terapêutas", através de conversas espontâneas e dirigidas, atividades relacionadas ao cavalo (pentear e enfeitar o pelo e crina do cavalo; abraçar, beijar, limpar o cavalo; alimentar o cavalo) e atividades lúdicas que envolviam situaçóes do dia-a-dia da criança.

De maneira geral, os atendimentos proporcionaram o objetivo geral promover o desenvolvimento da linguagem oral e minimizar as dificuldades de socialização ocasionadas pelo autismo e outra necessidade especial. No que diz respeito ao desenvolvimento da linguagem oral por estes praticantes, foram traçados objetivos específicos como: promover o desenvolvimento dos aspectos cognitivos (atenção, concentração e memória), promover desenvolvimento da linguagem expressiva (emissão e intenção comunicativa) e promover o desenvolvimento das vocalizaçôes. Esses objetivos foram trabalhados com os praticantes em cada sessão e realizados através de conversas espontâneas, brincadeiras lúdicas com livros de histórias infantis, bolinhas de sabão, jogos de encaixe, bolas, jogos de associação de cores, fantoches, livros de números, jogos de memória. Também foram realizadas atividades e conversas dirigidas usando categorias semânticas de frutas, animais, cores, materiais de higiene pessoal e objetos utilizados no dia-a-dia da criança.

Para minimização das dificuldades de socialização foram traçados objetivos específicos como: promover melhor densenvolvimento nas relaçôes interpessoal e promover melhor interação social, que foram trabalhados durante todas as sessóes com aproximação do "praticante e animal" e "praticante e terapêutas", através de conversas espontâneas e dirigidas, atividades relacionadas ao cavalo (pentear e enfeitar o pelo e crina do cavalo; abraçar, beijar, limpar o cavalo; alimentar o cavalo) e atividades lúdicas que envolviam situaçóes do dia-a-dia da criança.

Atualmente, muitos dos praticantes possuem linguagem oral expressiva melhorada devido à terapia e socialização, conseguindo até formar frases, realizar perguntas diretas, responder a comandos e manter um diálogo. No que diz respeito à socialização, os praticantes evoluíram satisfatoriamente, conseguindo interagir com as pessoas do seu ambiente familiar e escolar. Também obteve resultados positivos quanto a sua agressividade e dificuldade em ser contrariado, apresentando irritaçóes apenas eventualmente.

Quanto ao aspecto motor, percebeu-se que a utilização do cavalo, proporcionou melhoria na postura corporal de quase todos praticantes, mesmo com aqueles que apresentavam e ainda apresentam considerável comprometimento motor-físico. Buscando estar mais bem posicionado no cavalo, com melhoria no tônus muscular e, sobretudo, na autoestima e autovalorização de cada praticante. Estes dados nos permitem afirmar que a equoterapia, em parceria com a Apae, tem contribuído significativamente com a melhora nas condiçóes sociais-terapêuticas e corpóreas dos praticantes.

\section{Os cuidados com o cavalo}

A prática da equoterapia é realizada graças à interação direta entre o praticante e o cavalo, onde este, como todo animal, necessita de cuidados e uma atenção à parte voltada para manutenção do seu bem estar e de sua saúde, de modo que o mesmo esteja sempre apto a realizar as atividades desta modalidade terapêutica. Assim a presença de profissionais como médico veterinário e zootecnista é de fundamental importância tendo em vista a maior segurança que os mesmos podem trazer para o manejo com o animal. Estas açóes foram feitas pelo bolsista e voluntários envolvidos sob a coordenação dos professores orientadores.

O cavalo no ambiente da equoterapia é visto como um atleta, onde o mesmo irá promover benefícios aos praticantes, principalmente, no que diz respeito a sua andadura, ou seja, a sua locomoção, desta forma é necessário que este animal tenha uma boa assistência quanto a sua nutrição, sanidade e medidas profiláticas.

As principais e fundamentais açôes realizadas voltadas para o cavalo são as voltadas para sua 
nutrição, de forma a orientar e supervisionar o que está sendo fornecido ao animal bem como a quantidade ofertada. Nesta área podemos ressaltar que a nutrição destes animais se faz através do fornecimento de uma adequada quantidade de volumoso, o qual o mesmo deve ser de boa qualidade e em quantidade suficiente tanto para suprir as exigências do animal como a de evitar sobras no cocho e o fornecimento controlado de concentrado; visando dar um suporte nutricional ao cavalo de forma que o mesmo esteja sempre apto à realização das atividades.

O auxílio no manejo sanitário da baia também é de grande importância e visa manter um ambiente sempre limpo e assim diminuir os riscos de possíveis enfermidades, principalmente, ligadas aos cascos do animal. Também deve ser realizado periodicamente o casqueamento do cavalo sendo importante ferramenta na manutenção de uma boa andadura. Cuidados como o controle de parasitas e manejo vacinal também foram realizados pelos universitários bolsista e voluntários envolvidos.

\section{Relação ensino e aprendizagem e formação cidadã dos extensionistas}

As atividades realizadas junto ao projeto de extensão deram a oportunidade de por em prática os conhecimentos adquiridos durante a graduação e assim, de favorecer a formaçáo profissional cada fez mais segura e experiente, sobretudo, no tocante à responsabilidade social. Durante graduação muitas vezes o foco de aprendizagem éo ambiente universitário (dentro do campus) e esquece-se que um dia quando os universitários estiverem formados e prontos para atuarem precisarão também reconhecer-se como membro social e responsável na construção de uma sociedade inclusiva. Este projeto não só favorece a populaçáo atendida pela equoterapia como também contribui, imensamente, em relação ao convívio social, ampliando a visão dos universitários para a sociedade e respeito à diversidade.

\section{Avaliação do projeto por meio dos familiares envolvidos}

Para avaliaçáo final do projeto, foi aplicado um questionário de avaliação para que os pais el ou responsáveis pudessem se expressar sobre as atividades do projeto. Em relação aos atendimentos dos profissionais, $90 \%$ afirmam que o atendimento é muito bom e $10 \%$ bom. Sobre a estrutura física 80\% afirmam muito bom; $20 \%$ afirmam ser bom. Quanto ao cavalo, $100 \%$ diz que ele está limpo; $90 \%$ que está saudável; $80 \%$ bom cuidado; $60 \%$ que está escovado; $100 \%$ afirmam cavalo estava calmo. Quanto ao tempo de atendimento: 50\% afirma ser adequado; $40 \%$ afirmam ser curto. Sobre o local de espera, $90 \%$ afirmam ser muito bom e $10 \%$ ser bom. Sobre indicar a equoterapia para outras famílias, $80 \%$ afirmam que fariam com $100 \%$ certeza, 1 com $90 \%$ certeza e 1 com $80 \%$ certeza. O que podemos constatar é que os familiares aprovaram as atividades da equoterapia e indicariam as atividades a outras pessoas. Mas, é necessário ampliar o tempo de atendimento para pelo menos 30 minutos de sessão.

Em avaliação geral sobre as açóes do projeto, a equipe aponta que é necessário maior envolvimento da UFPB, com possibilidade de investimento financeiro para a compra de materiais e recursos necessários, como: guia, capa, mordedura para o cavalo e a ampliaçáo de bolsas de extensão para a ampliaçáa no número de atendimentos à comunidade. Há três anos, o número de atendimentos permanece o mesmo, devido ao pequeno número de equitadores e profissionais, que em sua maioria sáo voluntários. Quanto ao local, ainda podemos apontar a dificuldade em manter as açóes em época de chuvas, pois o picadeiro (local onde se realiza as sessóes) é aberto nas laterais, não evitando a entrada de água de chuvas, alongando-se o espaço arenoso utilizado na prática de equoterapia.

Ainda podemos apontar como melhorias para as futuras açóes do projeto de extensão universitária a construção de um jardim sensorial que poderia fazer parte do percurso por onde o animal e o praticante passam durante a prática da equoterapia, que possibilitaria o contato com a natureza e ofereceria estímulos olfativos e táteis aos praticantes (podendo ser esta mais uma ação extensionista da UFPB junto a APAE: a construção de um jardim sensorial como prática de inclusão, em que os próprios estudantes de agronomia do campus 2 pudessem contribuir com seus conhecimentos). 


\section{Discussões}

Inicialmente, devemos rememorar a associação do conceito de Direitos Humanos ao simples fato do ser humano, ser humano. Como já apresentado anteriormente, o ser humano é singular e único com direitos específicos que possam garantir a sua dignidade e vida ${ }^{2}$. Neste contexto, ao se pensar em pessoas com deficiências, vários sáo os documentos que apontam os princípios legais de direitos específicos a esta população. Podemos elencar vários documentos nacionais e internacionais, que elucidam especificamente cada um dos direitos das pessoas com deficiência: a Constituição Federal Brasileira $^{1}$, em seu art. $3^{\circ}$ que tratam sobre a não discriminação e ratifica os preceitos de dignidade humana; o art. $5^{\circ}$ sobre igualdade de direitos, o artigo 206 e art, 208 que tratam sobre o direito à educação especificamente. A LDBEN ${ }^{14}$, no capítulo da educação especial e, a mais atual, a Lei Brasileira de Inclusão, lei no $13.146^{15}$ que apontam os direitos desta população em diferentes segmentos sociais. Além da Declaração de Salamanca ${ }^{16}$ que trata das normas e princípios de atendimento educacional especial às pessoas com deficiência além da exigência dos Estados da elaboração e implementação de políticas públicas na área; e as Declaraçóes de Guatemala ${ }^{17}$ e de Dakar ${ }^{18}$. O Brasil como signatário destes documentos, passou a assumir a responsabilidade social no tocante à educação, ao trabalho e à saúde para pessoas com deficiência, além de outros segmentos sociais.

A universidade como parte do Estado, acaba por assumir colaterialmente a mesma responsabilidade, por ser uma das instituiçóes responsável pelas açóes do Estado na área da inclusão. Isto ocorre por meio do ensino, da pesquisa e da extensão.

Quando pensamos em extensão universitária, nos remetemos o olhar para a responsabilidade das Universidades, quanto a sua funcionalidade como se prevê na Constituição Brasileira ${ }^{1}$, no art. 207 que estabelece que as "atividades universitárias de ensino, pesquisa e extensão" devem ser indissociáveis, podendo ser as atividades de extensão financiadas pelo poder público ${ }^{1}$. Consonante, a Lei de Diretrizes e Bases da Educação Nacional ${ }^{14}$ estabelece a extensão universitária como uma das finalidades da Universidade e ainda, ratifica a possibilidade de apoio financeiro do Poder Público, inclusive mediante bolsas de estudo ${ }^{14}$.

Analogamente, as ações da UFPB junto à Apae de Areia, por meio das atividades do projeto de
Extensão Equoterapia tendo buscado consolidar a prática da construção de uma sociedade inclusiva, a qual entendemos que se caracteriza pelo reconhecimento da diversidade e dos direitos de todos em diferentes segmentos sociais ${ }^{19}$. Isto pode ser constatado pelos dados apresentados no tocante aos resultados específicos em áreas da saúde, como a fonoaudiologia, fisioterapia e psicossocial que apresentaram, como citado anteriormente, resultados positivos aos praticantes da equoterapia.

Quando identificamos resultados positivos quanto ao atendimento aos praticantes e usuários da equoterapia, podemos afirmar que os direitos de acesso e proteçáo nas áreas específicas que se propóe por meio das açóes interdisciplinares nos atendimentos, vemos que os progressos nas áreas (fonoaudiologia, fisioterapia, psicossocial) têm apresentados resultados significativos aos praticantes. Quanto à formação cidadã esperada nas açôes das universidades como se prevê nas legislaçóes, os resultados apresentados têm se mostrado consolidantes quanto aos aspectos profissionais dos universitários, aos aspectos sociais e pessoais, pois constatamos que estes atores sociais corroboram com as atividades de extensão, nas discussóes e na proposição de práticas e dos cuidados com o animal. Vale ainda ressaltar que ao avaliar os resultados apontados sobre os desafios a serem enfrentados para novas ediçóes do projeto de extensão, nas falas dos extensionistas, fazem parte das açóes de extensão, que esbarra na problemática de financiamento das açóes por meio da universidade que têm sofrido com os cortes de orçamento por parte do Governo Federal, nos últimos anos. Mas, como se apresenta no documento de Política de Extensão Universitária ${ }^{20}$ :

Reconhecer o papel da Universidade Pública no enfrentamento das crises contemporâneas não significa superestimar suas capacidades ou subestimar o que importa enfrentar e superar. Trata-se, sobretudo, de ver a Universidade como parte ativa e positiva de um processo maior de mudança.

E ainda, que está sujeito às dificuldades, pelo fato se de dispor a fazer açóes sociais e a contribuir em uma sociedade que apresenta desigualdade social, na qual os menos favorecidos financeiramente acabam esbarrando em dificuldades quase que intransponíveis no tocante ao acesso às terapias e aos tratamentos 
alternativos, como a equoterapia. As dificuldades a serem enfrentados pelo projeto, têm sido discutidas com a Apae e juntos com a UFPB, têm conseguido articular açóes para a manutenção do mesmo.

Nesse ínterim, os dados resultantes da avaliação das famílias dos praticantes demonstram a importância da extensão como uma forma de consolidação dos direitos das pessoas com deficiência quanto à educação e à saúde; garantias essenciais para materialização dos Direitos Humanos.

\title{
Considerações finais
}

Podemos afirmar que com a equoterapia, oferecida por meio da extensão universitária em parceria com a APAE/Areia, tem trazidos inúmeras contribuiçóes às pessoas com deficiência, principalmente, por proporcionar atendimento clínico especializado gratuitamente e favorecendo ao desenvolvimento biopsicomotor. Não podemos deixar de apontar o investimento feito pelo MPT financiando o prédio da equoterapia.

Os ganhos em termos de saúde e aspetos educacionais são visíveis e faz-se necessário a continuidade das açóes para que os praticantes possam permanecer com acesso não só ao atendimento clínico, mas também ao avanço no campo social e educacional, os quais, a equoterapia tem proporcionado. As ações deste projeto têm consolidado a responsabilidade social da UFPB, no tocante à inclusão e a construção de prática de aceitação e respeito à diversidade. Todavia, ainda encontra limites para a sua ampliação e execução como já apontado anteriormente. Por fim, fazer extensão universitária somente com ações voluntárias, sem investimento financeiro, tem se tornado o maior desafio para a inclusão social.

\begin{abstract}
Equine-assisted therapy as an extension action for social and school inclusion

This article aims to present the actions of a university extension project that has as main objective social and school inclusion, in partnership with the Public Labor Ministry, APAE and the Federal University of Paraiba through the practice of equine therapy. The actions were carried out from 2016 to 2018, through weekly sessions lasting 20 to 30 minutes, to 24 people with disabilities, being attended by a specialist in the area of physiotherapy, speech therapy, psychology, physical educator, pedagogue and horseback riding (university students volunteers). The results show that there were improvements regarding body posture, orality, self-perception, muscle tone, social aspects among others. As for the social formation of university students, we can point out social involvement and responsibility in the human aspect. The challenges to be faced are the lack of investment to acquire material resources to expand the project and strengthen social networks to accept diversity.
\end{abstract}

KEYWORDS: APAE; School inclusion; Disabled people.

\section{Referências}

1. Brasil. Constituição Federal Brasileira. Brasilia: Senado Federal: 1988.

2. Organização das Nações Unidas. Declaração dos Direitos Humanos [Internet]. 1948 [citado 14 abr 2020]. Disponível em: https://www2.senado.leg.br/bdsf/bitstream/handle/id/508144/000992124.pdf?sequence=1 \&isAllowed=y

3. Brito DS, Rosa ACS. A APAE: Missão, histórico e características de atendimento : um olhar sobre a APAE de Areia-PB. Campina Grande: In Anais... do Cobesc, 2013.

4. Associação Nacional de Equoterapia. VI curso básico de equoterapia. ANDE; João pessoa, 2015. 
5. Associação Nacional de Equoterapia. Associação Nacional de equoterapia [Internet]. [citado 03 abr 2017]. Disponível em: www.equoterapia.org.br.

6. Cirillo C. Entrevista do mês de Julho/08 - Cel. Cirillo - ANDE - BRASIL.

7. Alves BD. Reflexóes sobre a prática da equoterapia e o desenvolvimento de crianças com paralisia cerebral. UFRJ, 2014.

8. Bezerra ML. Equoterapia: tratamento terapêutico na reabilitação de pessoas com necessidades especiais. Fanorp: Fortaleza, dissertação de especialização, 2011.

9. Wickert H. O cavalo como instrumento cinesioterapêutico. Apostila do IV curso básico de equoterapia. ANDE: João Pessoa, 2015.

10. Silva C H. Equoterapia para cegos: teoria e técnica de atendimento. Campo Grande: UCDB, 2004.

11. Ferreira JB. Os beneficios da equoterapia no tratamento de portadores de Síndrome de Down. Rio de Janeiro: Universidade Veiga de Almeira, (2008). Trabalho de Conclusão de Curso.

12. Uzun ALL. Equoterapia: aplicação em distrúbios do equilíbrio. São Paulo: Vetor, 2005.

13. Freire HBG. Equoterapia: teoria e técnica: uma experiência com crianças autistas. São Paulo: Vetor, 1999.

14. Brasil. Lei de Diretrizes e Bases da Educação Nacional, 9.394. Brasilia: Senado Federal, 1996.

15. Brasil. Lei Brasileira de Inclusão, 13.146. Brasilia: Senado Federal, 2015.

16. Unesco. Declaração de Salamanca [Internet]. 1994. [citado 20 jan 2020]. Disponível em: https://unesdoc.unesco.org/ ark:/48223/pf0000139394.

17. Unesco. Declaração de Guatemala [Internet]. 1999. [citado 14 abr 2020]. Disponível em : https://iparadigma.org.br/ biblioteca/gestao-publica-convencao-da-guatemala-de-1999-convencao-interamericana/.

18. Unesco. Declaração de Dakar. [Internet]. 2000. [citado 14 abr 2020]. Disponível em: http://www.direitoshumanos. usp.br/index.php/Direito-a Educa\%C3\%A7\%C3\%A3o/declaracao-de-dakar.html.

19. Sassaki RK. Inclusão: construindo uma sociedade inclusiva. Rio de Janeiro: WVA. (19). 2001

\begin{tabular}{|c|c|}
\hline $\begin{array}{r}\text { ENDEREÇO } \\
\text { Ana Cristina Silva Daxenberger }\end{array}$ & \\
\hline Departamento de Ciências Sociais e Fundamentais & Submetido: 30/06/2020 \\
\hline Rodovia 079, s/n & Aceito: 07/ 07/ 2020 \\
\hline
\end{tabular}

38 • Rev Bras Educ Fís Esporte, (São Paulo) 2020 Jul;34 nesp:29-38 